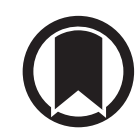

CrossMark

\title{
Impact of sleep alterations on weaning duration of mechanically ventilated patients: how much is bad?
}

\author{
To the Editor:
}

Sleep alterations and deprivation are common in mechanically ventilated patients in the intensive care unit (ICU). However, there is scarce information on how this is associated with mechanical ventilation and outcomes [1]. We therefore read with great interest the report on the effects of sleep alteration on weaning by THiLle et al. [2]. Those authors have shown that atypical sleep is associated with longer weaning duration but there are some key aspects to take into account in this regard.

Firstly, paroxysmal activity is frequent in unsedated patients who are unresponsive to voice, but the clinical implications of this remain to be determined [3]. Secondly, noise and light are integral parts of any ICU, and environmental noise has been shown to affect arousals and awakenings from sleep [4]. Noise and light levels could be monitored and standardised in future studies. Thirdly, information about bicarbonate levels would have been informative, as this has a negative correlation with sleep efficacy, sleep quality and weaning success [5]. Similarly, further information about patient-ventilator asynchrony or pre-existing sleep-disordered breathing is missing, which could have further confounded these findings [6, 7]. Lastly, weaning duration was defined as the time that elapsed between polysomnography (PSG) and extubation in this study. In this context, the length of stay in the ICU and mechanical ventilation prior to the recording of the PSG is important, and table 1 indicates that the patient groups were not similar in this aspect (i.e. atypical sleep groups had a significantly longer duration of ICU stay, mechanical ventilation, cumulative dose and duration of sedation). Although the authors evaluated consciousness and delirium prior to the PSG, and found no difference, we feel that comparing patients with similar ICU stay, mechanical ventilation duration and sedation would have given us better insight, as it would help to avoid selection bias of patients in weaning failure. Neither group of patients received continuous sedatives but the potential implications of sedative drugs (benzodiazepines etc.) used before weaning could be important to understand the observed sleep disturbance [8].

Sleep alterations are a frequent observation in critically ill patients; an important question that needs to be addressed is, what are the real consequences and treatment of disturbed sleep in the ICU [9]? This includes our understanding of whether they can resolve over time. The current study restarts the discussion of a controversial hot topic in critical care medicine; yet, it is important to more precisely classify atypical sleep and clinical implications to direct future research.

Antonio M. Esquinas ${ }^{1}$, Joerg S. Steier ${ }^{2,3}$ and Habib M.R. Karim ${ }^{4}$

${ }^{1}$ Intensive Care Unit, Hospital Morales Meseguer, Murcia, Spain. ${ }^{2}$ Respiratory and Sleep Medicine, Life Sciences and Medicine, King's College London, London, UK. ${ }^{3}$ Lane Fox Unit/Sleep Disorders Centre, Guy's and St Thomas' NHS Foundation Trust, London, UK. ${ }^{4}$ Dept of Anaesthesiology and Critical Care, All India Institute of Medical Sciences, Raipur, India.

Correspondence: Antonio M. Esquinas, Intensive Care Unit, Hospital Morales Meseguer, Avenida del Parque, 2, 3B, Murcia 30500, Spain. E-mail: antmesquinas@gmail.com

Received: May 172018 | Accepted: May 172018

Conflict of interest: None declared.

@ERSpublications

Sleep disturbance/atypical sleep is common in critically ill patients; however, precise classification of atypical sleep and clinical implication establishment will require direct future research http://ow.ly/pYSF30ketxz

Cite this article as: Esquinas AM, Steier JS, Karim HMR. Impact of sleep alterations on weaning duration of mechanically ventilated patients: how much is bad? Eur Respir J 2018; 52: 1800925 [https://doi.org/10.1183/13993003.00925-2018]. 


\section{References}

1 Lauridsen SV, Tønnesen EK, Nibro HL. Behov for mere viden om sovn hos intensivpatienter [There is a need for further studies exploring the sleep in patients during intensive care unit admission]. Ugeskr Laeger 2013; 175: $1488-1491$.

2 Thille AW, Reynaud F, Marie D, et al. Impact of sleep alterations on weaning duration in mechanically ventilated patients: a prospective study. Eur Respir J 2018; 51: 1702465.

3 Boesen HC, Andersen JH, Bendtsen AO, et al. Sleep and delirium in unsedated patients in the intensive care unit. Acta Anaesthesiol Scand 2016; 60: 59-68.

4 Freedman NS, Gazendam J, Levan L, et al. Abnormal sleep/wake cycles and the effect of environmental noise on sleep disruption in the intensive care unit. Am J Respir Crit Care Med 2001; 163: 451-457.

5 Huttmann SE, Wilms K, Hamm C, et al. Assessment of sleep in patients receiving invasive mechanical ventilation in a specialized weaning unit. Lung 2017; 195: 361-369.

6 Johnson DC, Johnson KG. Obstructive sleep apnea and prolonged mechanical ventilation. Respir Care 2012; 57: 326-327.

7 Delisle S, Ouellet P, Bellemare $\mathrm{P}$, et al. Sleep quality in mechanically ventilated patients: comparison between NAVA and PSV modes. Ann Intensive Care 2011; 1: 42.

8 Trompeo AC, Vidi Y, Locane MD, et al. Sleep disturbances in the critically ill patients: role of delirium and sedative agents. Minerva Anestesiol 2011; 77: 604-612.

9 Boyko Y, Ording H, Jennum P. Sleep disturbances in critically ill patients in ICU: how much do we know? Acta Anaesthesiol Scand 2012; 56: 950-958.

\section{From the authors:}

Sleep is markedly altered in intensive care unit (ICU) patients under mechanical ventilation [1-4]. Sleep in these patients is fragmented by numerous arousals and awakenings and mainly comprises light sleep. The deep sleep allowing physical restoration and the rapid eye movement (REM) sleep allowing neurobehavioral restoration may completely disappear. In some ICU patients, normal sleep architecture may disappear and be replaced by electroencephalogram aspects suggesting atypical sleep [5-7]. Whereas it has been shown that sleep deprivation could alter physical and cognitive functions in animals [8], the potential deleterious effects of such sleep disturbances in critically ill patients are unknown.

In a recent issue of the European Respiratory Journal, we reported that sleep alterations, especially atypical sleep or the absence of REM sleep stage, may be associated with poor outcomes in patients under mechanical ventilation with weaning difficulties [9]. Patients with atypical sleep or no REM sleep on polysomnography had prolonged duration of mechanical ventilation as compared to patients with normal sleep. In their correspondence, A.M. Esquinas and colleagues justifiably raise a number of concerns, and it is a great pleasure to reply and to provide supplementary findings to support our results.

It is true that multiple factors may disrupt sleep in the ICU, particularly noise, light, patient care activities, patient-ventilator asynchronies or central apnoeas, which can provoke numerous arousals and awakenings [1-4]. In ICU patients it has been shown that the sleep fragmentation index, i.e. the number of arousals and awakenings per hour of sleep, is very close to that in patients with severe obstructive sleep apnoea syndrome ( $>30$ events $\cdot h^{-1}$ ) [1-4]. In our study, sleep fragmentation was high but did not differ between patients with atypical sleep and those with normal sleep (median 33 events. ${ }^{-1}$ (interquartile range (IQR) 25-40 events. $\mathrm{h}^{-1}$ ) versus 31 events. $\mathrm{h}^{-1}$ (IQR 8-46 events. $\left.\left.\mathrm{h}^{-1}\right) ; \mathrm{p}=0.57\right)$. Although this result was not indicated in our article, it makes it clear that the environment was similar in the two groups.

Another major concern is that patients with atypical sleep could be more likely to have pre-existing sleep disorders, alkalosis or higher levels of bicarbonates, which may induce sleep alterations. In our overall population (45 patients), only two patients had known sleep apnoea syndrome and 12 (27\%) had underlying chronic obstructive pulmonary disease (COPD). Although the proportion of COPD patients was similar in the two groups ( $25 \%$ among those with atypical sleep versus $28 \%$ among those with normal sleep; $>0.99$ ), we cannot exclude the possibility that patients with atypical sleep may have had sleep difficulties before ICU admission. By contrast, the level of bicarbonates on the day of polysomnography did not differ between

@ERSpublications

A strong relationship might exist between sleep and weaning from mechanical ventilation in the ICU, and sleep alterations may be an underexplored aspect of weaning difficulties http://ow.ly/TzQq30ktNB5

Cite this article as: Thille AW, Coudroy R, Reynaud F, et al. Impact of sleep alterations on weaning duration of mechanically ventilated patients: how much is bad? Eur Respir J 2018; 52: 1800979 [https://doi. org/10.1183/13993003.00979-2018]. 
TABLE 1 Comparison of patients with normal sleep versus atypical sleep after matching by intensive care unit (ICU) length of stay and cumulative dose of midazolam

\begin{tabular}{|c|c|c|c|}
\hline & Normal sleep" & Atypical sleep ${ }^{\#}$ & p-value \\
\hline Patients n & 18 & 18 & \\
\hline \multicolumn{4}{|l|}{ Patient characteristics } \\
\hline Age years & $61(56-65)$ & $68(54-76)$ & 0.37 \\
\hline Male sex & $12(67 \%)$ & $14(78 \%)$ & 0.71 \\
\hline Body mass index $\mathrm{kg} \cdot \mathrm{m}^{-2}$ & $31(27-36)$ & $27(24-36)$ & 0.83 \\
\hline SAPS II at admission & $48(34-56)$ & $49(38-65)$ & 0.14 \\
\hline Length of ICU stay days ${ }^{\eta_{1}+}$ & $10(5-14)$ & $13(8-19)$ & 0.29 \\
\hline Duration of $\mathrm{MV}$ days ${ }^{+}$ & $9(4-14)$ & $13(7-18)$ & 0.33 \\
\hline Number of days with sedation ${ }^{+}$ & $5(3-11)$ & $8(5-14)$ & 0.44 \\
\hline Cumulative dose of midazolam $\mathrm{mg}^{\mathrm{\eta},+}$ & $528(264-1848)$ & $1308(498-2796)$ & 0.21 \\
\hline \multicolumn{4}{|l|}{ Respiratory parameters at time of PSG } \\
\hline Maximal inspiratory pressure $\mathrm{cmH}_{2} \mathrm{O}$ & $41(33-53)$ & $41(34-57)$ & 0.97 \\
\hline$P_{0.1} \mathrm{cmH}_{2} \mathrm{O}$ & $3.6(3.4-3.8)$ & $3.6(3.4-3.8)$ & 0.51 \\
\hline $\mathrm{pH}$ & $7.43(7.40-7.47)$ & $7.43(7.41-7.48)$ & 0.68 \\
\hline Bicarbonates level $\mathrm{mmol} \cdot \mathrm{L}^{-1}$ & $32(28-35)$ & $27(25-34)$ & 0.27 \\
\hline $\mathrm{PCO}_{2} \mathrm{mmHg}$ & $48(43-56)$ & $42(40-47)$ & 0.19 \\
\hline $\mathrm{PaO}_{2} / \mathrm{FIO}_{2} \mathrm{mmHg}$ & 203 (186-238) & 217 (179-252) & 0.70 \\
\hline \multicolumn{4}{|l|}{ Clinical parameters at time of PSG } \\
\hline SOFA score & $3(2-4)$ & $3(3-4)$ & 0.60 \\
\hline RASS score & $0(0-0)$ & $0(-0.8-0)$ & 0.34 \\
\hline ICDSC score & $1(0-3)$ & $3(1-4)$ & 0.13 \\
\hline Delirium & $4(22 \%)$ & $8(44 \%)$ & 0.29 \\
\hline MRC score & $55(43-60)$ & $34(25-57)$ & 0.11 \\
\hline ICU-acquired weakness ${ }^{\S}$ & $6(33 \%)$ & $11(61 \%)$ & 0.18 \\
\hline \multicolumn{4}{|l|}{ Outcomes } \\
\hline Duration of MV after PSG days & $2(1-2)$ & $4(2-8)$ & 0.01 \\
\hline Prolonged weaning of $>48 \mathrm{~h}$ & $2(11 \%)$ & $12(67 \%)$ & 0.002 \\
\hline \multicolumn{4}{|c|}{ 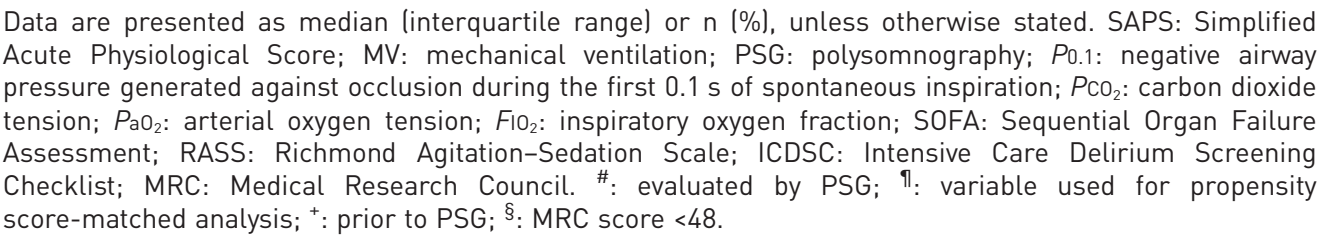 } \\
\hline
\end{tabular}

patients with atypical sleep and those with normal sleep ( $29 \pm 6$ versus $\left.30 \pm 6 \mathrm{mmol} \cdot \mathrm{L}^{-1} ; \mathrm{p}=0.41\right)$. Likewise, the proportion of patients with alkalosis $(\mathrm{pH}>7.42)$, which is a major factor for central apnoeas and subsequent arousals [10], was similar in the two groups (45\% in patients with atypical sleep (nine out of 20 patients) versus $42 \%$ in those with normal sleep (10 out of 24 patients); $p>0.99$ ). It must also be emphasised that all patients were conscious, responsive to voice and non-sedated, so that paroxysmal activity was unlikely.

Lastly, and this is probably the most important limitation of our study, patients who exhibited atypical sleep on polysomnography had spent more time in the ICU and had received more sedation prior to polysomnography than patients with normal sleep. Consequently, atypical sleep may be rendered more likely by sleep deprivation due to a more prolonged ICU stay, or may simply be the result of acute brain dysfunction due to more marked impregnation with sedative drugs rather than the result of sleep disturbances. We fully agree that we clearly cannot claim that sleep alterations are necessarily the cause of prolonged weaning and delayed extubation.

Given the baseline differences between patients with atypical sleep and those with normal sleep, we performed a propensity score-matched analysis according to their ICU length of stay and cumulative dose of sedation (midazolam) received prior to polysomnography (R software, MatchIt package; www.r-project.org). Baseline characteristics and outcomes of the 36 patients included in the propensity score-matched cohort ( $80 \%$ of the initial population) are displayed in table 1. After matching by ICU length of stay and cumulative dose of sedation prior to polysomnography, the duration of weaning remained significantly longer in patients with atypical sleep than in patients with normal sleep. Using multivariate analysis in this matched cohort, ICU-acquired weakness and atypical sleep were the two independent factors associated with prolonged weaning from mechanical ventilation, with an adjusted odds ratio for atypical sleep of 16.5 (95\% CI 2.7-174; $\mathrm{p}=0.006$ ). 
In view of these findings, we therefore believe that a strong relationship might exist between sleep and weaning from mechanical ventilation in the ICU and that sleep alterations may be an underexplored aspect of weaning difficulties.

Arnaud W. Thille, $e^{1,2}$ Rémi Coudroy ${ }^{1,2}$, Faustine Reynaud $^{1,2}$, Damien Marie ${ }^{1,2}$, Stéphanie Barrau ${ }^{1,2}$, Ludivine Rousseau ${ }^{1,2}$, Christophe Rault ${ }^{1,3}$, Véronique Diaz ${ }^{1,3}$, Jean-Claude Meurice ${ }^{1,4}$, Jean-Pierre Frat ${ }^{1,2}$, René Robert ${ }^{1,2}$ and Xavier Drouot ${ }^{1,3}$

${ }^{1}$ INSERM CIC 1402, Groupe ALIVE, Université de Poitiers, Poitiers, France. ${ }^{2}$ Réanimation Médicale, CHU de Poitiers, Poitiers, France. ${ }^{3}$ Neurophysiologie Clinique et Explorations Fonctionnelles, CHU de Poitiers, Poitiers, France. ${ }^{4}$ Pneumologie, CHU de Poitiers, Poitiers, France.

Correspondence: Arnaud W. Thille, Réanimation Médicale, CHU de Poitiers, 2 rue la Milétrie, 86021 Poitiers Cedex, France. E-mail: aw.thille@gmail.com

Received: May 252018 | Accepted: May 252018

Conflict of interest: J-P. Frat reports personal fees and non-financial support from Fisher \& Paykel, and personal fees from SOS Oxygène, all outside the submitted work.

\section{References}

1 Pisani MA, Friese RS, Gehlbach BK, et al. Sleep in the intensive care unit. Am J Respir Crit Care Med 2015; 191: 731-738.

2 Parthasarathy S, Tobin MJ. Effect of ventilator mode on sleep quality in critically ill patients. Am J Respir Crit Care Med 2002; 166: 1423-1429.

3 Gabor JY, Cooper AB, Crombach SA, et al. Contribution of the intensive care unit environment to sleep disruption in mechanically ventilated patients and healthy subjects. Am J Respir Crit Care Med 2003; 167: 708-715.

4 Cabello B, Thille AW, Drouot X, et al. Sleep quality in mechanically ventilated patients: comparison of three ventilatory modes. Crit Care Med 2008; 36: 1749-1755.

5 Cooper AB, Thornley KS, Young GB, et al. Sleep in critically ill patients requiring mechanical ventilation. Chest 2000; 117: 809-818.

6 Drouot X, Roche-Campo F, Thille AW, et al. A new classification for sleep analysis in critically ill patients. Sleep Med 2012; 13: 7-14.

7 Watson PL, Pandharipande P, Gehlbach BK, et al. Atypical sleep in ventilated patients: empirical electroencephalography findings and the path toward revised ICU sleep scoring criteria. Crit Care Med 2013; 41: 1958-1967.

8 Vimont-Vicary P, Jouvet-Mounier D, Delorme F. Effets EEG et comportementaux des privations de sommeil paradoxal chez le chat [EEG and behavioral effects of deprivation of paradoxical sleep in cats]. Electroencephalogr Clin Neurophysiol 1966; 20: 439-449.

9 Thille AW, Reynaud F, Marie D, et al. Impact of sleep alterations on weaning duration in mechanically ventilated patients: a prospective study. Eur Respir J 2018; 51: 1702465.

10 Meza S, Mendez M, Ostrowski M, et al. Susceptibility to periodic breathing with assisted ventilation during sleep in normal subjects. J Appl Physiol 1998; 85: 1929-1940. 